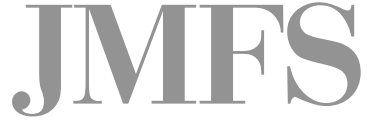

Journal of Management and Financial Sciences
Volume XI

Issue 33 (September 2018)

pp. 79-96

Warsaw School of Economics

Collegium of Management and Finance

Barbara Pawłowska, Michał Suchanek

The Faculty of Economics

University of Gdansk

\title{
Transport as a Factor in the Achievement of the EU Goals to Combat Climate Changes and to Reduce Greenhouse Gases Emissions
}

\footnotetext{
ABSTRACT

One of the priorities of the "Europe 2020" strategy is to combat climate change and to reduce greenhouse gases (GHG) emissions. The key elements for the climate policy framework for the European Commission for 2020 are as follows: (1) reducing GHG emissions by $40 \%$ in comparison to the level in 1990; (2) increasing the share of renewable energy in the use of final energy to $27 \%$; (3) increasing the energetic efficiency by $27 \%$. Those are ambitious goals which will require the Member States to increase their efforts in all the sectors of the economy. In 2015 the GHG emissions in the EU fell by $23.7 \%$ in comparison to the level in 1990 . All the sectors, apart from the transport sector contributed to the emission reduction in the years 1990-2015. The transport emission increased by $13.3 \%$ in that period in comparison to the year 1990, which is particularly worrisome. This is important because the fuels use in the transport sector contributed to approximately $20 \%$ of all the GHG emissions in the EU in 2015. The article presents the factors and the tools which significantly affect the achievement of the goals set in the Green Paper: a 2030 framework for energy and climate policies, which concern the transport sector and the indicated guidelines and instruments supporting them. The road transport will be extensively analysed as it is the transport mode which shows an extraordinary growth tendency and it is a vital barrier in the achievement of the goals set in the area of "Climate change and GHG emission reduction". The article presents the results of the research, which show the impact of various identified tools on the achievement of the three priorities of the climate policy. The multivariate analysis of variance (MANOVA) was used, in which the dependent variables were: the GHG emission levels, the use of renewable energy and the energy
} 
intensity of transport. The results were calculated based on the data from 28 Member States and the model was verified.

Keywords: transport, sustainable development, transport policy, GHGs, energy efficiency, alternative fuels.

JEL Classification Codes: Q28, Q58, R41

\section{Introduction}

Climate change is one of the greatest challenges facing the worldwide economy [OJ L 282/2016].The stake is the future of social welfare. This fact was recognized by the international community in Paris in December 2015, where an agreement on climate change was reached [EC, 2015]. The agreement sets out a global action plan to put the world on track to avoid dangerous climate change. Governments agreed on a long-term goal of keeping the increase in the global average temperature to well below $2^{\circ} \mathrm{C}$ above pre-industrial levels. The Paris Agreement showed that moving to a modern and low-carbon society is not just indispensable, but also now possible and individual countries as well as their unions should undertake the actions in all sectors to receive these goals.

The transport sector makes a huge contribution to the economy, to employment and to the mobility of citizens. In the case of the European Union (EU) the transport and storage sector employ more than 11 million people in the EU, more than $5 \%$ of the total employment and generates almost 5\% of the EU's GDP. It accounts for about $20 \%$ of exports to the EU's main trading partners [EC, 2017]. It should also have in mind that transport activity causes significant external costs.

According to the International Transport Forum (ITF) report [OECD/ITF, 2017] current and foreseeable policies to mitigate carbon-dioxide $\left(\mathrm{CO}_{2}\right)$ emissions from global transport activity will not suffice to achieve the international community's climate ambitions. A key factor for the difficulty in reducing transport $\mathrm{CO}_{2}$ emissions over the long run is shifting global trade patterns. As trade moves to the regions with a lack of rail or waterway infrastructure, greenhouse gas emissions from road freight will almost double. Another challenge is urban mobility. According to the ITF's analysis, the private car use in cities is set to double by 2050, as fast-growing emerging economies meet mobility demand. As stated in the ITF's baseline scenario, emissions form transport activities will increase by $60 \%$ by 2050 [OECD/ITF, 2017]. Emissions from freight transport will increase most and represent half of all emissions in 2050. This alarming evolution takes place despite the large expected gains in energy efficiency. Indeed, the average $\mathrm{CO}_{2}$ intensity of transport will decrease significantly between 2015 and 2050. In the baseline scenario, passenger travel will emit $60 \mathrm{~g}$ of $\mathrm{CO}_{2}$ per passenger-kilometre in 2050 on average, compared to $100 \mathrm{~g}$ in 2015 . Similar improvements occur for the freight sector. 
However, because of the expected strong growth in transport demand, this is far from sufficient to stop the growth in emissions, let alone reversing the trend [EEA, 2018]. $\mathrm{CO}_{2}$ emissions are growing in almost all sectors but in the road transport sector, both freight and passenger, the situation is worse. The growth of more than 70\% between 2015 and 2050 is predicted.

According to the EEA's report [EEA, 2017] in 2015, the transport sector contributed $25.8 \%$ of the total EU-28 greenhouse gas emissions (GHGs). This figure decreases to $21 \%$ if international aviation and maritime emissions are excluded. Emissions from transport in 2015 were 23\% above the 1990 levels despite a decline between 2008 and 2013. Emissions increased by almost $2 \%$ compared with 2014 . International aviation experienced the largest percentage increase in greenhouse gas emissions over the 1990 levels $(+105 \%)$, followed by international shipping $(+22 \%)$ and road transport $(+19 \%)$. Road transport contributes about one-fifth of the EU's total emissions of carbon dioxide $\left(\mathrm{CO}_{2}\right)$, the main greenhouse gas. While these emissions fell by $3.3 \%$ in 2012, they are still $20.5 \%$ higher than in 1990 .

Emissions need to fall by around two thirds by 2050, compared with the 1990 levels, in order to meet the long-term $60 \%$ greenhouse gas emission reduction target as set out in the Transport White Paper [2011].

The goal of the article is to assess the trend of the changes in the aforementioned indicators and also to determine whether the use of various instruments have had an effect on the dynamics of these changes.

\section{The European Union's Climate and Energy Policy Framework for 2030 and 2050}

The European Union has established a clear framework for the policy regarding the energy and climate by 2020 . This framework integrates various political goals, such as a decrease in the greenhouse gas emissions, securing the energy supplies and promoting growth and competitiveness of the EU. In 2010, the European Commission proposed the Europe 2020 Strategy which was launched as the EU's strategy for smart, sustainable and inclusive growth [EC, 2010].

This strategy has begun a new chapter in the history of the EU. It has substituted the Lisbon strategy which was applied since 2010, but which proved to be inappropriate for the challenges of modern Europe [Pawłowska, 2013]. The 2007 crisis showed the structural weaknesses of the European economy and, in many areas, cancelled the results of many years of effort towards economic and social growth.

The main aim of the Europe 2020 Strategy was to improve the EU's competitiveness while maintaining its social market economy model and improving significantly its resource efficiency. As an effect of the Strategy a new economy should arise. An economy based on knowledge, low-emission, promoting environmentally friendly technologies, resource efficient, creating a new "green" working environment while also caring about social integrity [Pawłowska, 2015]. 
The three priorities set in the strategy focus on intelligent, sustainable and socially inclusive growth. These goals are related and create a coherent picture of the European social economy in the $21^{\text {st }}$ century. Seven main initiatives were attributed to the priorities. They are shown in Figure 1.

Figure 1. Key initiatives in relation to the Europe 2020 priorities

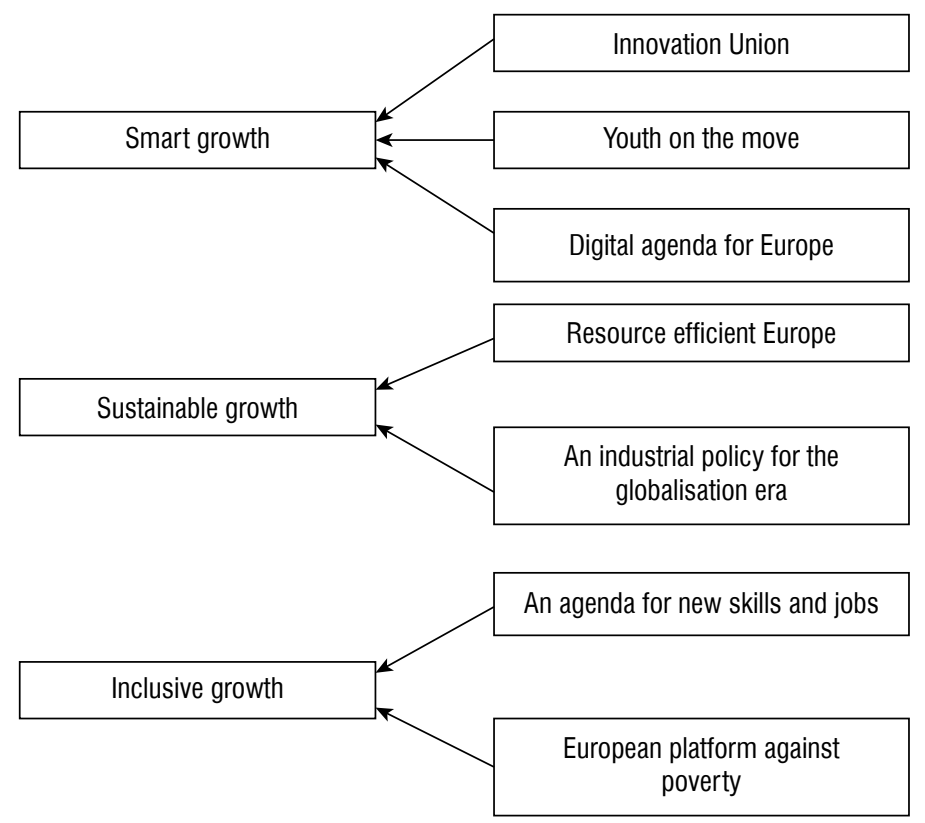

Source: Koźlak et al., 2013.

The analysis of the priorities and key initiatives lead to a conclusion that the activities helpful in the achievement of the first pillar goals are: 'Digital agenda for Europe', 'Innovation Union' and 'Youth on the move'. Macroeconomic studies which have been carried out for years show that in the developed countries, $80 \%$ of the economic growth can be attributed to innovations. Rational resource use is one of the next crucial goals regarding the environment protection and economic growth. An efficient use of resources increases the competitiveness and allows creating new jobs while protecting natural resources. Therefore, it strongly correlates with the EU's climate and energy policy. Currently, the use of energy has a significant effect on the competitiveness of the European economy. A transition into a more efficient resource use and a low-emission economy are the keys to the fulfilment of the second pillar goals. The third pillar focuses on combating poverty and promoting initiatives for new jobs creation and unemployment decrease.

A transition into a low-emission, resource-efficient economy requires vast changes in the areas of: technology, energy sources, management strategies, finances and social behaviour. The Paris climate agreement leads to possibilities of economic transformation and growth, an increase in employment and fulfilment of the sustainable growth goals. [OJ L 282/2016]. 
The main EU goals regarding the climate and energy have been declared in the climate-energy package by 2020 [EC, 2008] and also in the climate-energy policy by 2030 [Green Paper, 2013].These goals are meant to determine the directions of the EU economic transformation by 2050 according to the plan of transitioning into a low-emission economy. The 2020 package is a set of binding legislation to ensure the EU meets its climate and energy targets for the year 2020. The package sets three key targets:

- $20 \%$ cut in greenhouse gas emissions (from the 1990 levels);

- $20 \%$ of the EU's energy from renewables;

- $20 \%$ improvement in energy efficiency.

The European Commission presented the policy framework for the climate and energy by 2030 in the Green Paper [2013].The new goals and instruments for increasing the competitiveness and security are presented in the document. They are also supposed to balance the Union's economy and energy system. These goals include a reduction in greenhouse gas emissions and a higher consumption of energy from renewable sources. New management systems and new efficiency indicators are presented as well.

The EU needs a radical change to outline a credible, long-term vision for the future of renewable energy, based on the existing instruments. Europe has two main goals in terms of energy technologies: reducing the cost of clean energy and achieving a leading position by the European industry in the fast-growing low-carbon technology sector. The Union has set energy and climate targets that should be met by 2020, 2030 and 2050. Table 1 presents these goals by 2050 .

Table 1. EU targets for achieving low carbon economy by 2050

\begin{tabular}{|l|c|c|c|}
\hline \multicolumn{1}{|c|}{ Targets } & By 2020 & By 2030 & By 2050 \\
\hline Reducing GHGs emissions & $\begin{array}{c}\text { by at least 20\% } \\
\text { compared to 1990 }\end{array}$ & by 40\% & $80-95 \%$ \\
\hline Share of renewable energy in overall consumption & $-\mathbf{2 0 \%}$ & $\mathbf{2 7 \%}$ & by 27-30\% \\
\hline Improving the energy efficiency & by 20\% & $\mathbf{1 5 \%}$ & \\
\hline $\begin{array}{l}\text { The amount of energy in interconnections - i.e. the percentage } \\
\text { of electricity generated in the EU and sent to other EU countries }\end{array}$ & & & \\
\hline
\end{tabular}

Source: the authors' own study based on the EU's strategic documents.

The framework for 2030 must be sufficiently ambitious to ensure that the EU is on track to meet the longer-term climate objectives in 2050. It should take into account the changes which have happened in all areas of economic and social life and it must identify how best to maximise synergies and deal with trade-offs between the objectives of competitiveness, security of energy supply and sustainability.

The framework should also take into account the longer-term perspective which the Commission laid out in 2011 in the Roadmap for moving to a competitive low carbon economy in 2050 [EC, 2011a], the Energy Roadmap 2050 [EC, 2011b], and the Transport White Paper [2011]. The 2013 EU strategy on adaptation to climate change aims at making Europe 
more climate resilient [EC, 2013]. It promotes adaptation actions across the EU, ensuring that adaptation considerations are addressed in all the relevant EU policies (mainstreaming), promoting greater coordination, coherence and information-sharing. The main elements of the Strategy concerning transport activity are:

- increasing the efficiency of the transport system by making the most of digital technologies;

- smart pricing and further encouraging the shift to lower emission transport modes;

- speeding up the deployment of low-emission alternative energy for transport, such as advanced biofuels, renewable electricity and renewable synthetic fuels and removing obstacles to the electrification of transport;

- moving towards zero-emission vehicles; while further improvements to the internal combustion engine will be needed, Europe needs to accelerate the transition towards low- and zero-emission vehicles.

The document presented, among others:

- an obligation to further reduce the greenhouse gas emissions (lowering them by $40 \%$ in comparison to the 1990 level by 2030);

- a goal stating that at least $27 \%$ of the used energy should come from renewable sources; the Member States will be allowed to set their individual goals;

- a tendency to improve the energetic efficiency due to potential changes in the directive on energetic efficiency;

- a reform of the Union's emission certificates trade system, so that it includes the market stability reserve;

- key indicators (regarding the energy prices, the energy source diversification, the intersystem connections between the Member States and the technology development), which allow measuring the advancements in creating a more competitive, secure and sustainable energy system;

- a new framework for the reporting system used by the Member States based on the national plans, which are coordinated and reviewed at the level of the EU.

\section{Review of the EU's climate policy activities' effects}

The analysis of the three aforementioned areas: the transport GHG emissions, the consumption of the final energy in the transport sector and the share of alternative fuels in the transport sectors leads to a number of conclusions. Transportation is responsible for nearly a fourth of all the GHG emissions in Europe and is the main cause for the decline in the air quality in the cities, which is a severe public health danger. The road transport itself is responsible for nearly a fifth of all the pollution in the EU.

In 2015, road transport was responsible for $72.9 \%$ of total greenhouse gas emissions from transport (including aviation and international shipping). Of these emissions, $44.5 \%$ were contributed by passenger cars, while $18.9 \%$ came from heavy-duty vehicles and buses (Figure 2 ). 
Figure 2. Share of transport GHG emissions in 2015

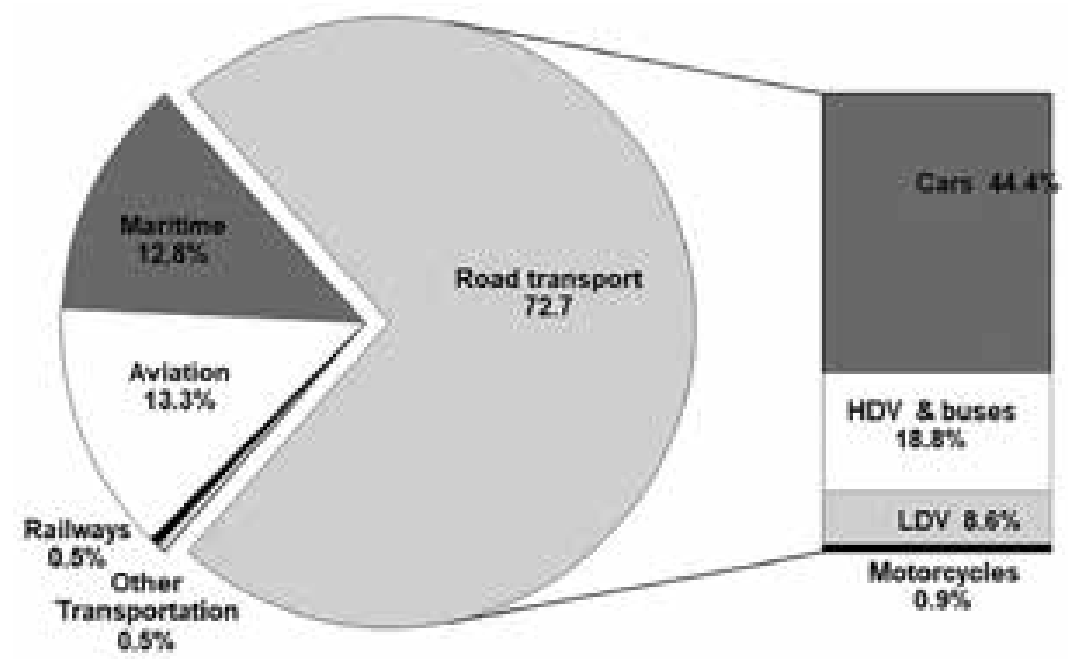

Source: EEA, 2018.

The attention should be put on fact that as a result of a significant rise in passenger-kilometre and tonne-kilometre demand, greenhouse gas emissions from international aviation more than doubled from the 1990 levels (105\%), followed by international shipping (22\%) and road transport (19\%). Emissions from transport (including aviation but excluding international shipping) in 2015 were 23\% above the 1990 levels despite a decline between 2008 and 2013. Emissions increased by almost 2\% compared with 2014 [TERM002/EEA, 2018].

To gain the EU's target, emissions need to fall by around two thirds by 2050, compared with the 1990 levels, in order to meet the long-term 60\% greenhouse gas emission reduction target as set out in the 2011 Transport White Paper. Figure 3presents the changes observed in the Member Statesin the period 1990-2015.

The transport GHG emissions vary significantly across different EU countries. The highest increase in emissions (an increase of over 100\%) happened in the Czech Republic, Ireland, Poland and Slovenia. In five Member States the situation has improved, including a nearly a $14 \%$ drop in emissions in Lithuania and a $0.25 \%$ drop in Finland. This tendency shows the need for a stronger support for the technology and driving changes in the road transport.

In the area of the share of alternative fuels in the energy consumption the EU Member States have national targets detailing how they propose to comply with the overall target of a $10 \%$ share of renewable energy supply in the transport sector by 2020 . In this point it should be pointed out that only biofuels complying with the sustainability criteria under the EU Renewable Energy Directive [2009/28/EC] are to be counted towards this target. The most recent data shows that in $2016,7.1 \%$ of the energy consumed in transport is renewable, compared with $6.6 \%$ the year before and $1.4 \%$ in 2004 , if only those biofuels that met the sustainability criteria are included. 
Figure 3. Changes in the total greenhouse gas emissions from transport in the 1990-2015 period in individual EU countries

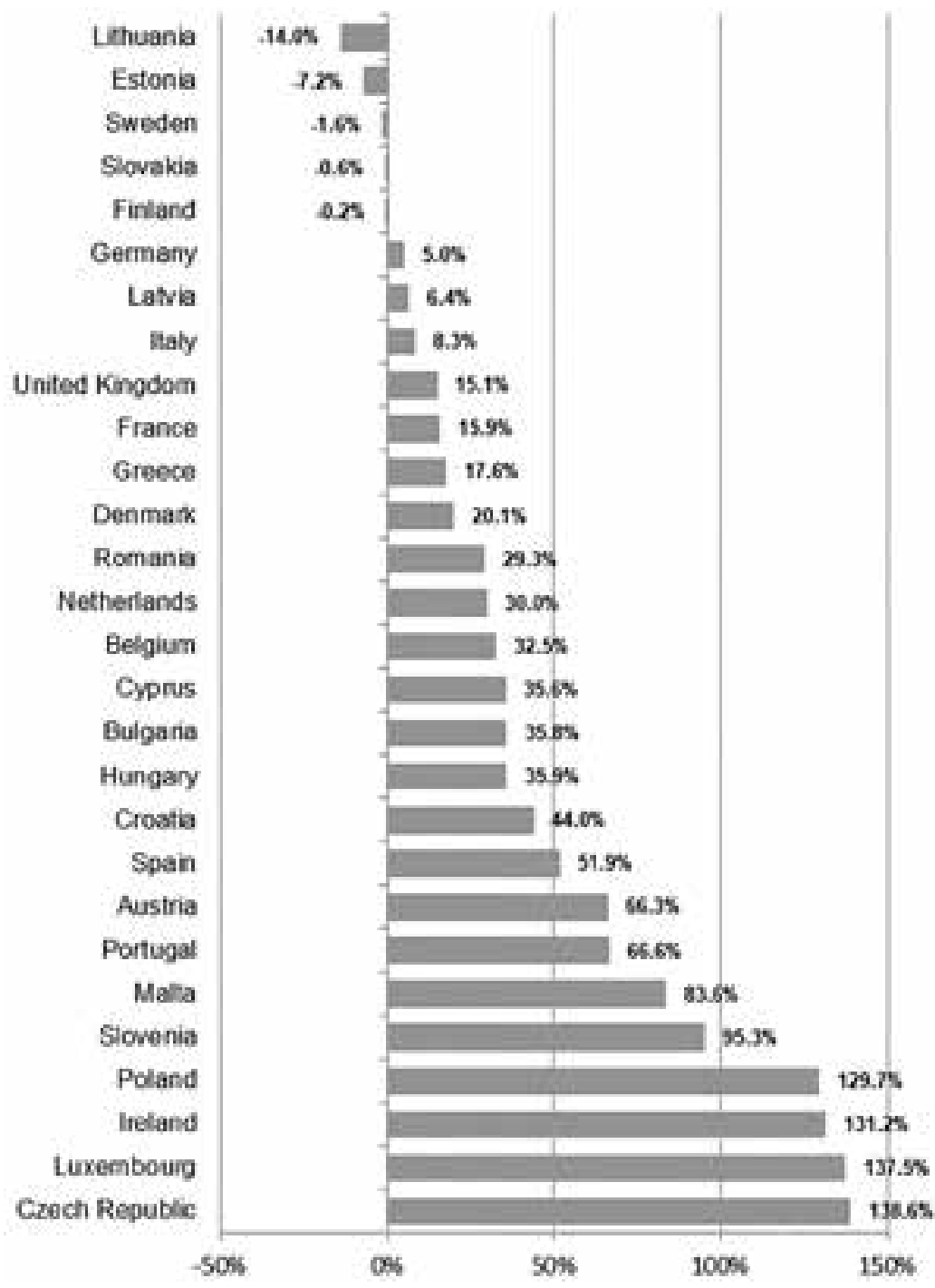

Source: EEA, 2018.

The EU Member States are required to achieve a $10 \%$ share in renewable energy by 2020 , for all transport options. At the EU level, the share of energy from renewable sources in transport stood at $7.1 \%$ in 2016, Figure 4presents the share of renewable energy in transport in the Member States in the period 2013-2016.

As it can be noticed in 2016, Sweden (30.3\%) and Austria (10.6\%) were the only two Member States to reach the target of using $10 \%$ of renewable fuel energy for transport. While France $(8.9 \%)$ and Finland $(8.4 \%)$ were relatively close to achieving the target, most of the other EU member states were around the half-way point to meeting the 2020 objective. With a use of less than $3 \%$ of energy from renewables in transport, Estonia (0.4\%), Croatia (1.3\%), 
Greece (1.4\%) and Slovenia (1.6\%), followed by Cyprus (2.7\%) and Latvia (2.8\%) were the furthest from the $10 \%$ target.

Figure 4. The share of renewable energy in transport in the EU Member States in 2013-2016

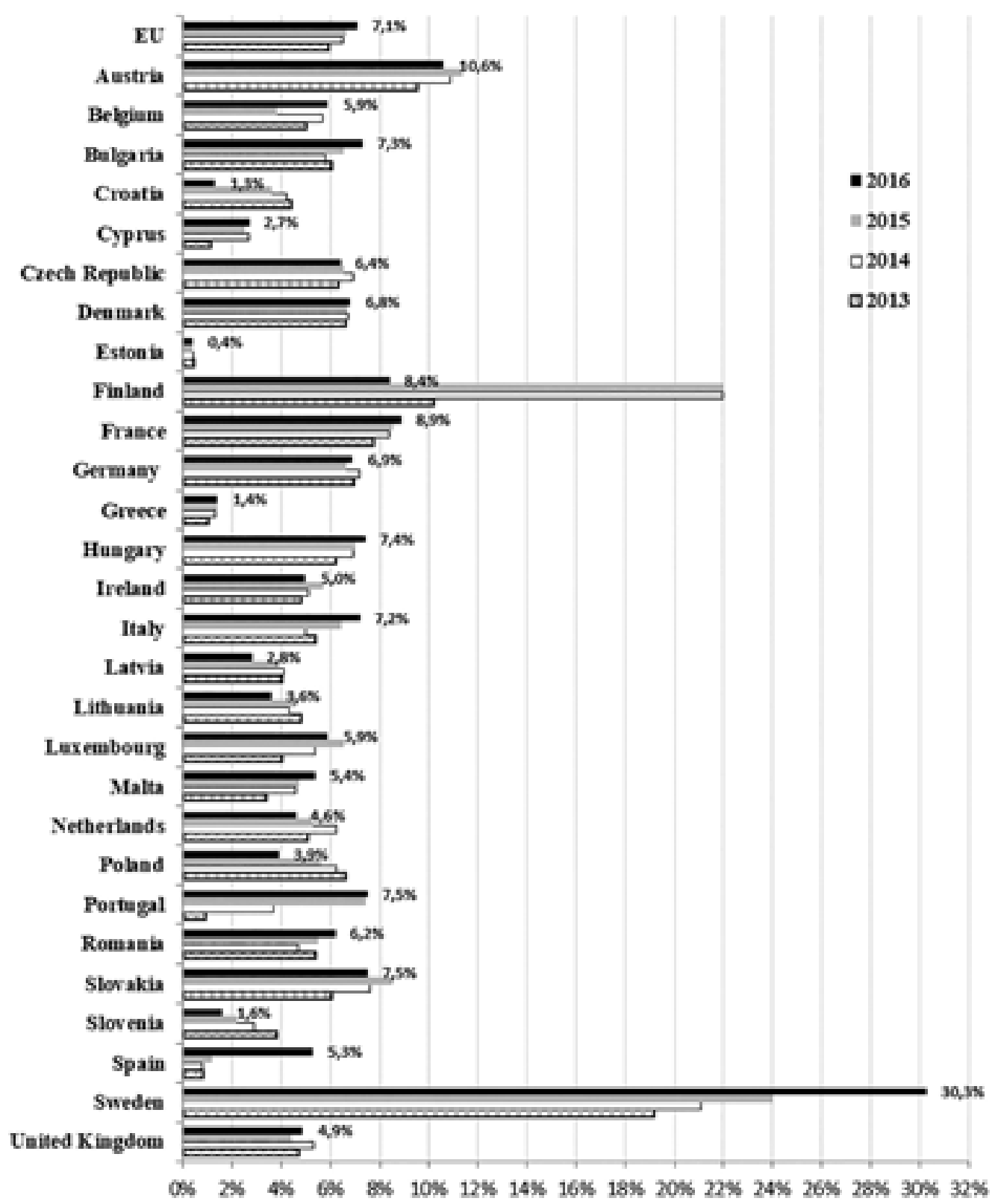

Source: EUROSTAT, 2018.

It is worth underlining that Sweden and Spain had the largest increases in their share of transport fuel from renewable energy sources between 2015 and 2016, while the use of this type of energy fell significantly in Finland. Summing up, in general the proportion of renewable 
energy used by the transport sector is growing but remains small. Several reasons lie behind the slow uptake of renewable fuels across the EU, including: (1) market uncertainty caused by delays in limiting the risk of greenhouse gas emissions due to indirect land use change; (2) relatively high abatement costs related to biofuels; and (3) slow progress in the deployment of second-generation biofuels.

The advancements in the fulfilment of the Union energetic efficiency goals in transport will be presented based on the report from 2017. The results have been published in the Communication [2017] and it includes information on the progress made by 2015 in order to reach the $20 \%$ goal. This analysis is based on the official European statistics on energy, which is sent by the Member States to the Eurostat, the analyses conducted by the Joint Research Centre (JRC) and works within the Odyssee-Mure project.

The goal for the 2020 is to reduce the final energy consumption in the EU to a level below 1086 Mtoe and the primary energy consumption to a level below 1483 Mtoe. According to the data, after a steady energy use decrease in the years 2007-2014, an increase occurred in 2015 , resulting partially from a colder winter and partially from lower fuel prices. The prime energy consumption decreased significantly after the recession (2009-2015) in almost all of the Member States which shows that the economic growth can be achieved without an increased demand for energy. The weather changes are pointed out as the main causes for the energy use changes in the years 2014-2015. Figure 5shows the data on the energy consumption in comparison to the GDP.

Figure 5. Trends in final energy consumption compared to EU GDP over the period 1995-2015

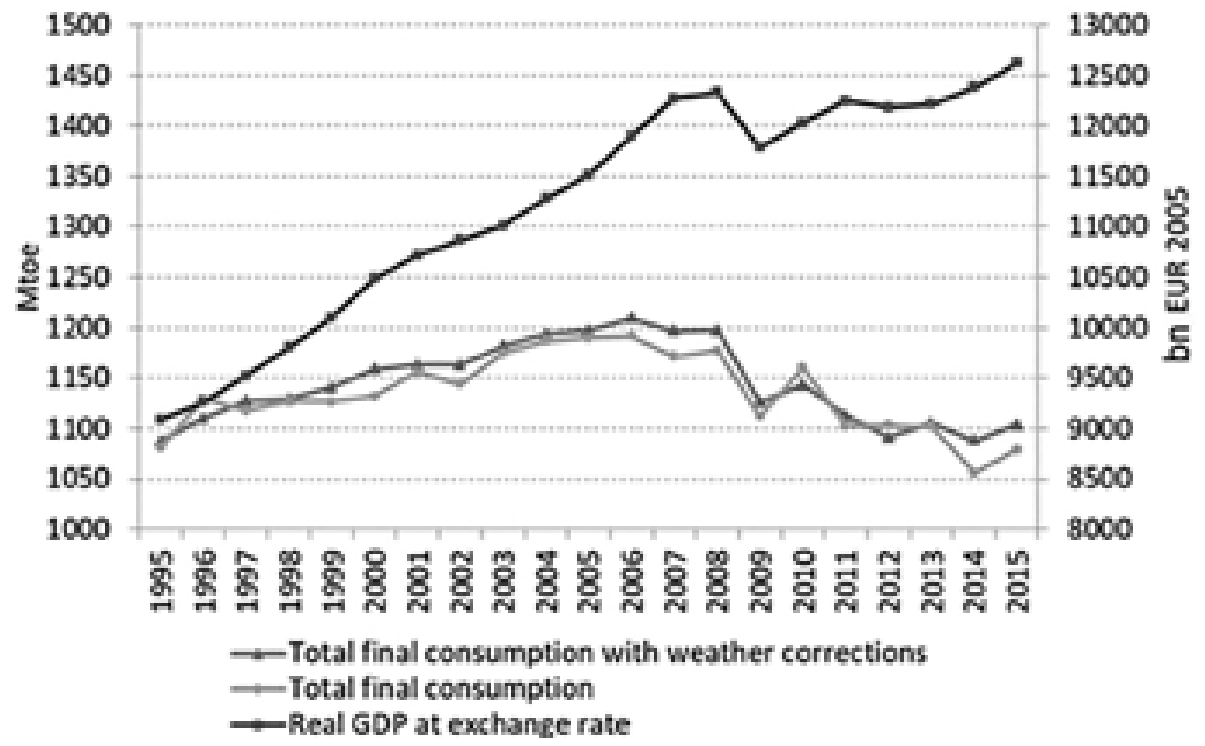

\footnotetext{
* The weather correction factor was calculated as a proportion of heating degree days (HDD) in a given year over the average HDD in the period 1990-2015. This correction factor was applied to the energy consumption used for space heating of the residential sector. Source: Odyssee-Mure, 2018.
} 
If the declining trend observed since 2005 continues in the coming years, the EU should still be on track to achieve the 2020 target both for primary and final energy consumption. There is a need to note that the average rate of the decrease in primary energy consumption/ final energy consumption in the 2005-2015 period is higher than the rate of the linear decrease from 2005 to the 2020 target.

An increase in the economic activity usually leads to an increase in energy consumption. This was counteracted by energy savings, which in 2015 and 2016 were not high enough to balance out the effects of an increased economic activity.

In the transport sector the use of final energy in the EU decreased by 3\%, from 369 Mtoe in 2005 to 359 Mtoe in 2015. In 2015, 15 Member States increased their energy consumption in the sector in comparison to the 2005 level. ${ }^{1}$ The consupmtion increased significantly (by over 20\% since 2005) in Malta, Poland, Romania, Lithuania and Slovenia. Decreases occurred in Greece (of 20\%) and Spain (of 16\%). The use of final energy in the transport sector in the EU increased by $2 \%$ in the years 2014-2015 in all the Member States except four (Germany, Italy, Luxembourg, Slovenia). The highest increases in the consumption occurred in Bulgaria (10\%), Hungary (8\%), Lithuania and Poland (both 5\%). This was mostly caused by: the increase in road transport carriage in 2015 , both in the passenger transport $(2.2 \%$ increase in the passengerkm) and in the cargo transport ( $2.8 \%$ increase in the tonnekm), a further decrease in the prices of oil products and a demand increase in the air transport.

The impact of the economic activity on the use of energy is also shown in the analysis performed in the Odyssee-Mure project: this factor ${ }^{2}$ ttributed to a growth of 9 Mtoe in 2015, while the energy saving decreased the consumption by 2 Mtoe and the impact of the modal switch was negligible (Figure 6, where energy savings are presented according to the Oddysee-Mure project).

The data presented in Figure 6shows an energy efficiency improvement of 1\%/year between 2000 and 2015, as measured by the ODEX, which combines the energy efficiency trends of the different modes of transport. Greater energy efficiency progress was achieved for both cars and airplanes than in the rest of the sector. A slowdown for trucks and light vehicles has been visible since 2005, with no more efficiency progress since 2007 because of the economic crisis. In 2015, energy savings in transport according to the Odyssey database reached around 50 Mtoe at the EU level: without energy efficiency improvement, the energy consumption would have been higher by 50 Mtoe. A slowdown in energy savings after 2007 is noticed, mainly due to no more progress for goods transport because of the economic recession.

1 There is a need to exercise caution when comparing data for different Member States, as final energy consumption is calculated on the basis of the amount of fuel sold, not on the basis of the amount of fuel used on the national territory. In this context, other factors than energy efficiency are involved, for example, the degree to which a Member State is a transit country for road transport or an air hub.

2 As a result of economic activity, there are changes in the flow of passengers, including air traffic and freight transport. 
Figure 6. Energy efficiency index by mode (EU)

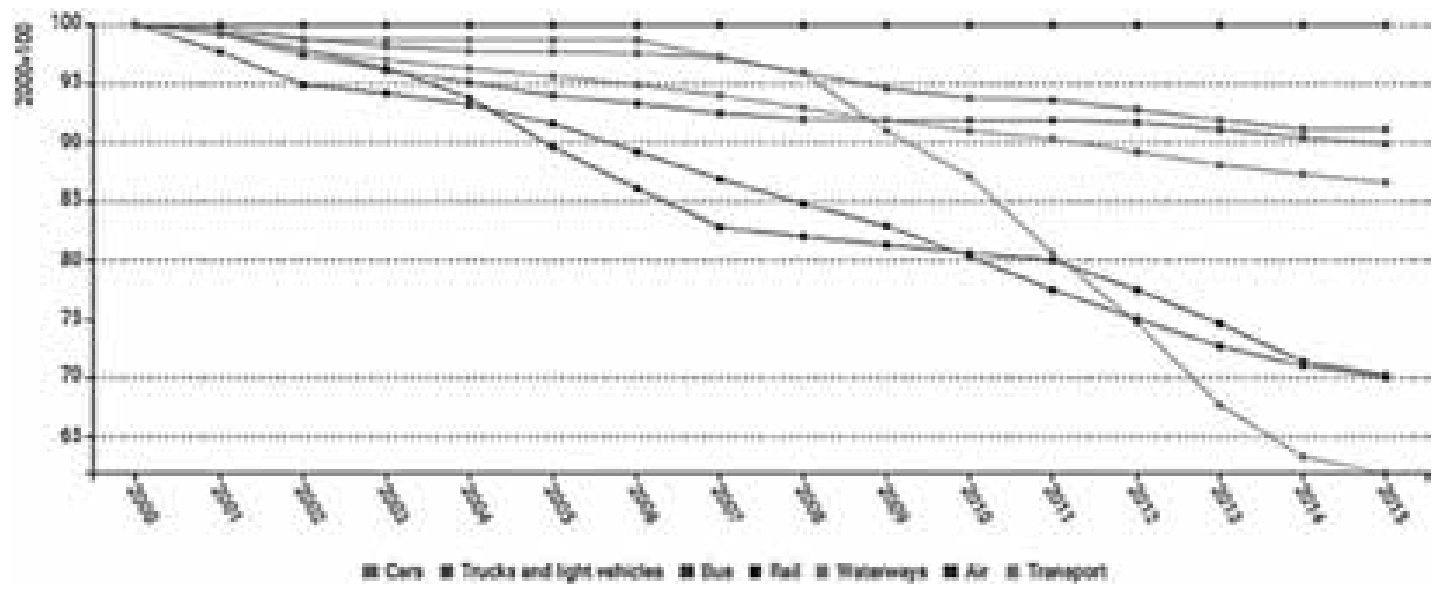

Source: Sectoral Profile: Transport, [Odyssee-Mure, 2018].

\section{The effect of the transport sector activity on the achievement of the EU's climate and energy policy goals}

The goal of the research on the achievement of the EU's climate and energy policy goals is to assess whether the effort which the countries undertake by introducing various pro-ecological instruments is effective. First, the instruments for climate change were identified and divided into two categories: the instruments used to promote non-conventionally fuelled vehicles and the instruments used to reduce the transport demand. Then, the authors analysed how many instruments were introduced by every EU Member State in both categories. Based on the collected data on the number of instruments of the promotion of non-conventionally fuelled vehicles and on the number of instruments of the reduction of the transport demand [Odyssee-Mure, 2018], two dummy variables were constructed:

- prom_ven_Syn 1 - representing the total number of instruments introduced in order to promote non-conventionally fuelled vehicles;

- red_dem_Syn2 - representing the total number of instruments introduced in order to reduce the transport demand.

Then, a cluster analysis was performed to identify the groups of countries based on their pro-ecological effort. Cases were grouped into two clusters based on the values of the two dummy variables (Figure 7). The first cluster groups the countries which generated a higher pro-ecological effort in terms of both groups of instruments. The differences in the number of the promotion of non-conventionally fuelled vehicles is not that high (on average 9 for the first cluster, 3 for the other cluster), but the difference in the number of instruments introduced in order to reduce the transport demand is significant (on average 59 for the first cluster and only 13 for the other cluster). 
Figure 7. Results of the cluster analysis - pro-ecological effort

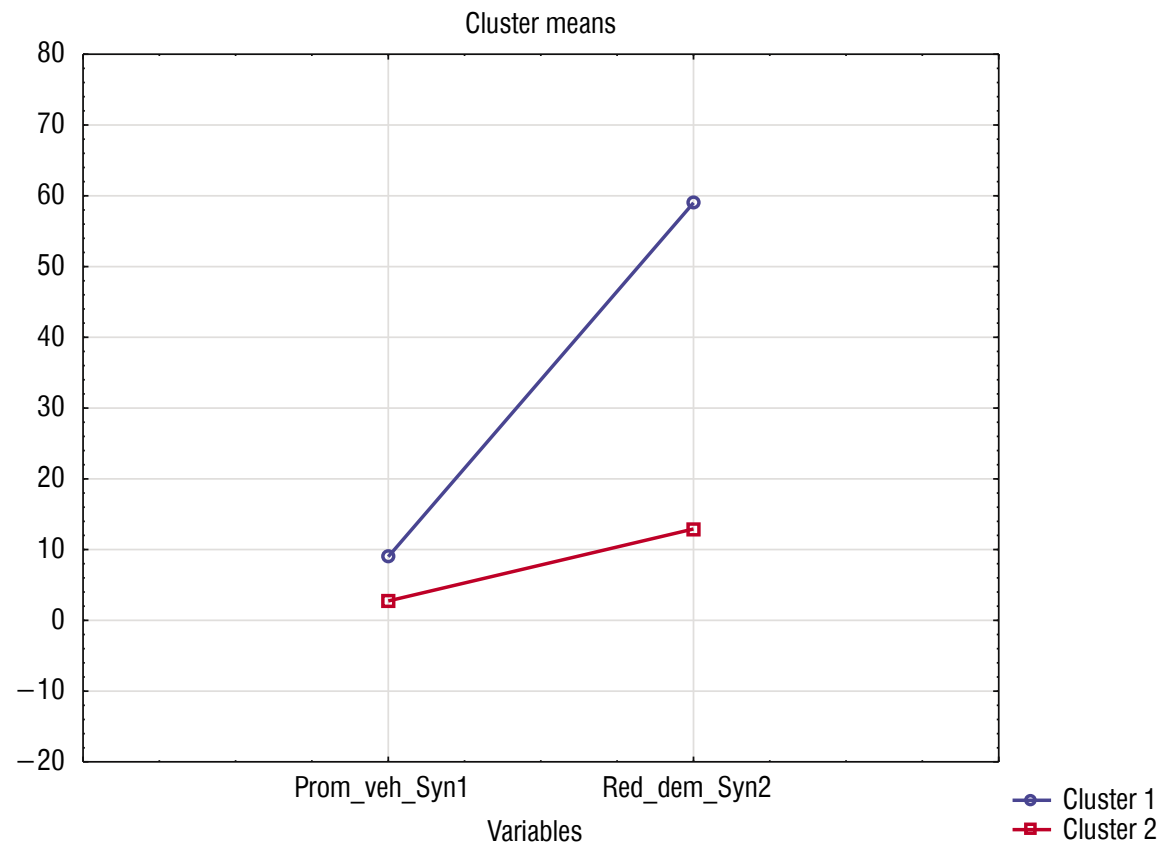

Source: the authors' own estimation.

Then, a multivariate analysis of variance was performed to verify if a higher pro-ecological effort of a group of countries provided better results. These results were represented by three variables:

- SH_AV_DYN (representing the average dynamics of the share of renewable energy in the use of final energy dynamics of a given country in the analysed period);

- FEC_AV_DYN (representing the average dynamics of energetic efficiency dynamics of a given country in the analysed period);

- GHG_AV_DYN (representing the average dynamics of the greenhouse gas emissions dynamics of a given country in the analysed period).

The factor which was taken into account as the basis of the MANOVA was the GROUP variable which represented to which group the country belonged, based on the results of the cluster analysis (Figure 8).

The Wilks Lambda parameter resulting from the MANOVA has a level of significance $\mathrm{p}=0.556$, which means that none of the analysed variables had a statistically significantly different average value across the analysed groups. This result is confirmed by the analysis of the multivariate parameters of the MANOVA (Table 2). 
Figure 8. Results of the multivariate analysis of variance

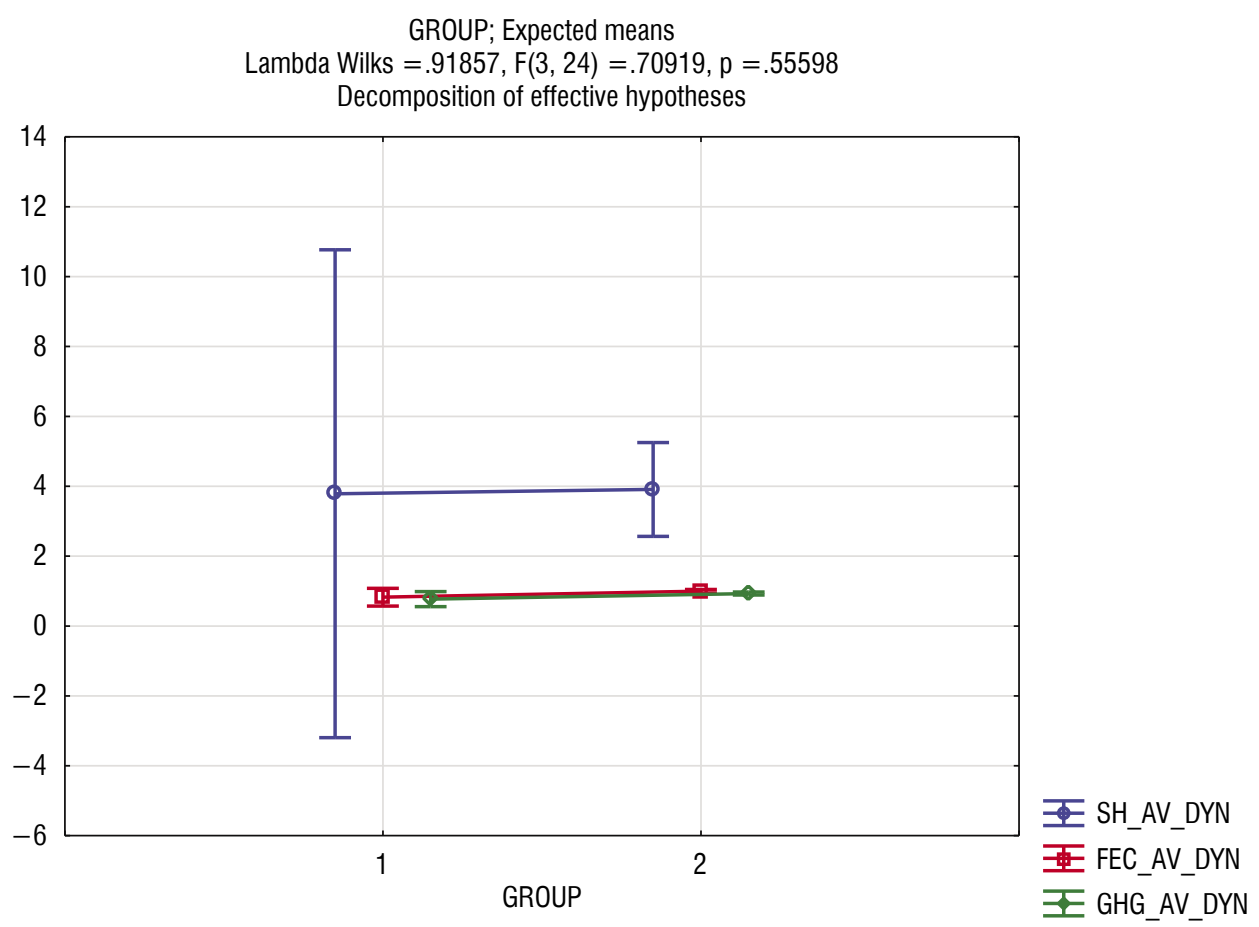

Source: the authors' own estimation.

Table 2. Multivariate significance tests for the MANOVA

\begin{tabular}{|l|l|c|c|c|c|c|}
\hline \multirow{2}{*}{ Effect } & \multicolumn{6}{|c|}{ Multivariate significance tests } \\
\cline { 2 - 7 } & \multicolumn{1}{|c|}{ Test } & Value & F & $\begin{array}{c}\text { Effect } \\
\text { df }\end{array}$ & $\begin{array}{c}\text { Error } \\
\text { df }\end{array}$ & $p$ \\
\hline GROUP & Wilks & 0.91857 & 0.70919 & 3 & 24 & 0.555982 \\
\hline & Pillai & 0.08143 & 0.70919 & 3 & 24 & 0.555982 \\
\hline & Hotelln. & 0.08865 & 0.70919 & 3 & 24 & 0.555982 \\
\hline & Roy & 0.08865 & 0.70919 & 3 & 24 & 0.555982 \\
\hline
\end{tabular}

Source: the authors' own estimation.

These results suggest that the pro-ecological effort which the countries generate, represented by the number of instruments which they use, does not affect the dynamics of the greenhouse gas emissions, energetic efficiency and the share of renewable energy in the use of final energy. This could mean that the instruments which are used are ineffective or that they have radically different effectiveness in different countries, thus, making the sheer number of instruments used an ineffective predictor.

It is worth mentioning that all the basic conditions of the use of MANOVA are met as represented by the Levene test results for the homogeneity of the variance (Table 3 ) and by the analysis of the normal distribution. 
Table 3. Verification of the MANOVA conditions

\begin{tabular}{|l|l|c|c|c|}
\cline { 2 - 4 } \multicolumn{1}{c|}{} & \multicolumn{3}{c|}{ Levene test for the homogeneity of the variance } \\
\cline { 2 - 5 } \multicolumn{1}{c|}{} & MS Effect & MS Error & F & p \\
\hline SH_AV_DYN & 6.826056 & 4.186124 & 1.630639 & 0.212902 \\
\hline FEC_AV_DYN & 0.007937 & 0.006779 & 1.170874 & 0.289156 \\
\hline GHG_AV_DYN & 0.006556 & 0.003994 & 1.641410 & 0.211442 \\
\hline
\end{tabular}

Source: the authors' own estimation.

Regardless of the effectiveness of the particular measures, a panel data regression model was analysed to predict the tendency of the development of the three factors: the share of renewable energy, the greenhouse gas emissions and the energetic efficiency. First, the Breusch-Pagan Lagrangian multiplier test for random effects was performed to determine whether the effects are fixed or random within different countries. The results of the test (significance level lower than 0.05 ) indicate that the panel regression should be constructed based on the assumption that the dynamics of the three factors are significantly different across different countries and should be treated as a fixed effect (Figure 9).

Figure 9. Breusch-Pagan Lagrangian multiplier test for random effects

\begin{tabular}{|c|c|c|c|c|c|}
\hline \multirow{2}{*}{\multicolumn{3}{|c|}{$\begin{array}{l}\mathrm{SH}[\mathrm{NR}, \mathrm{t}]=\mathrm{Xb}+\mathrm{u}[ \\
\text { Estimated results: }\end{array}$}} & \multirow{2}{*}{ Var } & \multirow{2}{*}{ sd } & \multirow{2}{*}{$=\operatorname{sqrt}(\operatorname{Var})$} \\
\hline & & & & & \\
\hline & & $\mathrm{SH}$ & 13.47856 & & 3.671316 \\
\hline & & e & 4.528017 & & 2.127914 \\
\hline & & $\mathrm{u}$ & 7.436543 & & 2.727003 \\
\hline \multirow[t]{3}{*}{ Test: } & $\operatorname{Var}(\mathrm{u})$ & $=0$ & & & \\
\hline & & & chibar2 (01) & $=$ & 379.39 \\
\hline & & & cob $>$ chibar2 & $=$ & 0.0000 \\
\hline
\end{tabular}

Source: the authors' own estimation.

Three panel regression models were generated with the assumption of the fixed effects. The following models show the changes in, appropriately: the share of renewable energy (Figure 10), energetic efficiency (Figure 11) and greenhouse gas emissions (Figure 12).

All of the analysed models are statistically significant, proved by the $\mathrm{F}$ and t tests for the significance of variables. The panel data models show the following results:

- on average, every year the share of renewable energy increases by $0.51 \%$;

- every year the energetic efficiency increases as represented by an average decrease of 132.1 units;

- on average, every year the greenhouse gas emissions decrease by 412.91 units. 
Figure 10. Share of renewable energy panel data model

\begin{tabular}{|c|c|c|c|c|c|c|}
\hline $\mathrm{SH}$ & Coef. & Std. Err. & t & $P>|t|$ & [95\% Conf. & Interval] \\
\hline Time & .5141071 & .0519158 & 9.90 & 0.000 & .4117988 & .6164154 \\
\hline _cons & -1029.534 & 104.4027 & -9.86 & 0.000 & -1235.276 & -823.7916 \\
\hline sigma_u & 2.8177395 & & & & & \\
\hline sigma_e & 2.1279139 & & & & & \\
\hline rho & .63681937 & (fraction & of varia & ce due to & $u_{-}$i) & \\
\hline
\end{tabular}

Source: the authors' own estimation.

Figure 11. Energetic efficiency panel data model

\begin{tabular}{|c|c|c|c|c|c|c|}
\hline FEC & Coef. & Std. Err. & t & $P>|t|$ & [95\% Conf. & Interval] \\
\hline Time & -132.0936 & 22.97649 & -5.75 & 0.000 & -177.3724 & -86.81481 \\
\hline _cons & 278575.2 & 46205.75 & 6.03 & 0.000 & 187519.5 & 369631 \\
\hline sigma_u & 17634.84 & & & & & \\
\hline sigma_e & 941.75569 & & & & & \\
\hline rho & .99715622 & (fraction & of varia & ce due to & $u_{-}$i) & \\
\hline
\end{tabular}

Source: the authors' own estimation

Figure 12. Greenhouse gas emissions panel data model

\begin{tabular}{|c|c|c|c|c|c|c|c|}
\hline GHG & Coef. & Std. Err. & t & $P>|t|$ & & [95\% Conf. & Interval] \\
\hline Time & -412.9208 & 66.72171 & -6.19 & 0.000 & & -544.4066 & -281.4351 \\
\hline _cons & 863367.6 & 134177.5 & 6.43 & 0.000 & & 598949.6 & 1127786 \\
\hline sigma_u & 44502.264 & & & & & & \\
\hline sigma_e & 2734.7762 & & & & & & \\
\hline rho & .9962378 & (fraction & of varia & ce due & to & $u_{-}$i) & \\
\hline
\end{tabular}

Source: the authors' own estimation

It is worth mentioning that despite the fact that the intensity of the use of various instruments promoting pro-ecological behaviour does not affect the results measured in the form of the three analysed factors, the overall tendency is positive as all the indicators show a trend in the direction called for by the European Union. 


\section{Summary}

Two separate clusters of the Member States can be identified based on a given country's pro-ecological effort. However, the intensity of the pro-ecological effort measured by the number of instruments used to promote non-conventionally fuelled vehicles and instruments used to reduce the transport demand does not determine the changes in three main indicators of the climate change. This leads to a conclusion that despite the fact that transport is one of the main determinants of the climate change, the instruments used to promote more ecological transport and to reduce transport demand are not effective enough. Regardless of that, the panel regression models allow predicting that the overall changes of the climate are going in the direction indicated by the policy framework. Further research is needed into the efficiency and effectiveness of the transport policy instruments used. It is also important to examine the mutual impact of the instruments in various categories and their interaction with the achieved results. It should be stressed that the usage of package-mix would allow obtaining a synergistic effect in achieving the goals, especially if the tools of the different category of instruments are used.

As we look at Poland, according to country profile conducted within the Odyssee-Mure project [Odyssee-Mure, 2018], we can note that final energy consumption in Poland increased by $0.8 \%$ /year from 2000 reaching 64 Mtoe in 2015 . The biggest consumer was the household sector, whose share amounted to $32 \%$ in 2015 , followed by transport with $27 \%$ share. The highest consumption in transport was achieved by cars (representing $47 \%$ of the sector's consumption in 2015) followed by trucks ( $40 \%$ share in 2015 in comparison with $32 \%$ in 2000 ). The share of air transport remained unchanged (4\%). Bus transport represented $7 \%$ of the consumption and $0.3 \%$ for motorcycles in 2015 . Transport energy consumption has almost doubled since 2000 mainly driven by the effect of the growth in traffic (for passengers and goods) and the modal shift from public vehicles to private cars and from trains to roads in the case of goods. Energy savings (4.1 Mtoe) counterbalanced partially the effect of these two factors. Energy efficiency in Poland improved by 2.2\%/year over the period 2000-2015. Energy efficiency of transport improved by $1.2 \%$ /per year until 2010, with an acceleration since (3.3\% /year).

When analyzing the measures/instruments used in Poland supporting the climate policy objectives, it should be noted that they mainly focus on the level of national and local authorities. They concern subsidizing solutions that increase energy efficiency (for instance: for energy efficient vehicles or clean vehicles, as well as bio-fueled/electric/LPG/natural gas vehicles) and fiscal instruments that make taxes dependent on the energy efficiency of vehicles. Information/education/training and infrastructure can be mentioned as other categories. As examples of such instruments, "Development of Intelligent Transportation Systems" or "Traffic management system and transport of goods optimization" could be mentioned. In both cases, the programmes aim to reduce final energy consumption. Unfortunately, in the case of Poland, single actions are taken. The lack of a systemic approach reduces the efficiency and effectiveness of these tools. 


\section{References}

1. EC, 2008, Communication from the Commission: 2020 by 2020 - Europe's climate change opportunity, COM (2008) 30, final.

2. EC, 2010, Communication from the Commission, Europe 2020, A strategy for smart, sustainable and inclusive growth, COM (2010) 2020.

3. EC, 2011a, Communication from the Commission to the European Parliament, the Council, the European Economic and Social Committee and the Committee of the Regions, A Roadmap for moving to a competitive low carbon economy in 2050 COM (2011) 112 final.

4. EC, 2011b, Communication from the Commission to the European Parliament, the Council, the European Economic and Social Committee and the Committee of the Regions, Energy Roadmap 2050, COM (2011) 0885 final.

5. EC, 2013, Communication, An EU Strategy on Adaptation to Climate Change, COM (2013) 216, final.

6. EC, 2015, Energy Union Package, Communication from the Commission to the European Parliament and the Council, The Paris Protocol - A blueprint for tackling global climate change beyond 2020, COM (2015) 81 final.

7. EC, 2017, Communication from the Commission to the European Parliament, the Council, the European Economic and Social Committee and the Committee of The Regions Delivering on low-emission mobility. A European Union that protects the planet, empowers its consumers and defends its industry and workers, COM/2017/0675 final.

8. EEA, 2017, Analysis of key trends and drivers in greenhouse, gas emissions in the EU between 1990 and 2015, EEA, Report No 8/2017.

9. EEA, 2018, https://www.eea.europa.eu/data-and-maps/indicators/ (accessed: 20.03.2018).

10. EUROSTAT database, 2018, http://ec.europa.eu/eurostat/web/products-eurostat-news/-/ DDN-20180312-1? inheritRedirect=true (accessed: 23.03.2018);

11. Green Paper, 2013, A 2030 framework for climate and energy, COM (2013) 169, final.

12. Koźlak et al., 2013, Koźlak A., Pawłowska B., Borkowski P., Bak M., Burnewicz J., Adamowicz E., A review of EU policy approach to improve international competitiveness in Europe, Deliverable 4.1. I-C-EU project, Gdańsk.

13. Oddyssey-Mure project, 2018, http://www.indicators.odyssee-mure.eu/decomposition.html (accessed:12.03.2018).

14. OECD/ITF (2017), ITF Transport Outlook 2017, OECD Publishing, Paris. http://dx.doi. org/10.1787/9789282108000-en (accessed: 20.03.2018).

15. OJL 282/2016, Paris Agreement, Brussels 19.10.2016.

16. Pawłowska B., (Ed.), 2016. Infrastruktura transportu a konkurencyjność regionów w Unii Europejskiej.Gdańsk: Wyd. Uniwersytetu Gdańskiego.

17. Transport White Paper, 2011, Roadmap to a Single European Transport Area - Towards a competitive and resource efficient transport system, COM/2011/0144 final. 